\title{
Characteristics of Yoga Practitioners, Motivators, and Yoga Techniques of Choice: A Cross-sectional Study
}

\author{
Shirley Telles*, Sachin Kumar Sharma, Nilkamal Singh and Acharya Balkrishna \\ Patanjali Research Foundation, Haridwar, India
}

Background: The characteristics of yoga practitioners and factors motivating people to practice yoga have been studied in the US and in Australia. This study aimed to determine the characteristics of yoga users in India, the factors that motivate them to practice yoga, and the yoga techniques of choice.

Materials and methods: The study was a one-time, cross-sectional survey based on convenience sampling. Inclusion criteria were (a) a minimum of 1 week experience of

OPEN ACCESS

Edited by:

Dan J. Graham,

Colorado State University,

United States

Reviewed by:

Milka Dancevic Gojkovic,

Public Health Institute of Federation

of Bosnia and Herzegovina,

Bosnia and Herzegovina

Sherry L. Edwards,

University of North Carolina at

Pembroke, United States

*Correspondence:

Shirley Telles

shirleytelles@gmail.com

Specialty section:

This article was submitted to Public Health Education and Promotion,

a section of the journal

Frontiers in Public Health

Received: 07 April 2017 Accepted: 06 July 2017

Published: 27 July 2017

Citation:

Telles S, Sharma SK, Singh N and Balkrishna A (2017) Characteristics of

Yoga Practitioners, Motivators, and

Yoga Techniques of Choice:

A Cross-sectional Study.

Front. Public Health 5:184.

doi: 10.3389/fpubh.2017.00184 yoga and (b) at least 10 years of age. 14,250 people received the survey. After excluding those who did not meet the inclusion criteria or filled in the survey incompletely or incorrectly, 5,157 respondents were included in the study.

Results: Out of 5,157 respondents, there were more males (67.3\%), aged between 21 and 44 years (33.7\% of the sample surveyed), educated up to high school (62.5\%), students (39.3\%), and those who had between 1 and 12 months of experience in yoga (54.4\%). The first most common reason to practice yoga for all respondents was physical fitness. Three of the remaining reasons to practice yoga differed significantly with age: (i) yoga for disease management $\left(\chi^{2}=17.62, p<0.005\right)$, (ii) yoga as a hobby $\left(\chi^{2}=10.87\right.$, $p<0.05$ ), and (iii) yoga based on the guru's (teacher's) instructions $\left(\chi^{2}=20.05\right.$, $p<0.001$ ). The yoga technique of choice [i.e., (i) asanas $\left(\chi^{2}=23.17, p<0.001\right)$, (ii) pranayama $\left(\chi^{2}=19.87, p<0.001\right)$, or (iii) meditation $\left(\chi^{2}=9.64, p<0.05\right)$ ] differed significantly across age groups.

Conclusion: In India, a yoga practitioner was more likely to be male, between 21 and 44 years of age, high school educated, and a student. The reasons to practice yoga and the yoga technique of choice differed significantly with age.

Keywords: yoga, characteristics of users, motivating factors, yoga techniques, survey, India

\section{INTRODUCTION}

Yoga has multiple and diverse benefits (1). June 21 was declared the International Day of Yoga by the United Nations General Assembly, following a resolution from the Government of India (2). This declaration was based on the holistic approach to health and well-being through yoga. Hence, the declaration aimed to disseminate information about the overall benefits of yoga, for health (2).

The Associated Chambers of Commerce and Industries Social Development Foundation (India) conducted a survey $(n=1,100)$ which suggests that the intention of this resolution was 
met in India (3). There was a 30\% increase in yoga practitioners in metropolitan cities following the first International Day of Yoga in India, between June 2015 and June 2016 (3). In the survey, the majority of yoga practitioners were students, young professionals, those in decision-making positions, and retired persons.

A survey was conducted in the US as a personal household interview, with 34,525 respondents (4). The survey was part of the 2012 National Health Interview Survey (4) and aimed at determining the reasons why people chose to meditate, the predictors for use, self-reported outcomes of meditation practice, meditation use within the life time and in a 12-month period, utilization patterns, and the prevalence of specific meditation practices. Another survey, which was part of the 2002 US National Health Interview Survey aimed at determining the characteristics of yoga users (5). There were 31,044 respondents, and the survey was administered as a face-to-face interview. The questions were intended to determine the prevalence of yoga users (found to be $5.1 \%, n=1,593$ ), characteristics of yoga users, medical reasons for practicing yoga, perceptions about the helpfulness, and the disclosure of use to medical professionals. A nation-wide survey was conducted in Australia as an online 30-min interactive web-based questionnaire, which was also intended to determine the characteristics of yoga practitioners, investigate the styles of yoga commonly practiced, the motivation to practice, perceived effects of practice, yoga-related injuries, as well as dietary and lifestyle choices (6). In both the US $(4,5)$ and Australia (6), yoga practitioners were more likely to be female, educated, and to be practicing yoga chiefly for physical well-being.

At least two surveys have been conducted in India. In a survey conducted in a city in the west of India (Mumbai), the aim was to determine whether university students were aware of scientific research on yoga (7). The survey was returned by 972 respondents, whose average age was 26 years and the ratio of males to females was $54.8 \%: 45.2 \%$. The other survey aimed to determine the barriers which yoga practitioners face when they are committed to practice yoga (8). The 280 participants had self-elected to join a 1 month residential course in yoga and participated in an online survey. Their average age was 34.5 years and the male to female ratio was 48.0:52.0.

To the best of our knowledge, there has been no survey in India to determine the characteristics of yoga users, their reasons for practicing yoga, and the yoga techniques they preferred. In June 2016 in India, several events preceded International Yoga Day to increase awareness about the multiple benefits of yoga.

The present survey on Indian respondents aimed at determining: (i) the characteristics of yoga users, (ii) the primary reason why people chose to practice yoga, and (iii) the yoga technique of their choice.

\section{MATERIALS AND METHODS}

\section{Sample}

The respondents to the survey had come from all over India to participate in or observe a public event on yoga. To be included in the survey participants had to have (i) a minimum of 1 week experience of yoga practice and (ii) completed at least 10 years of age. 14,250 individuals received the survey. Excluding those who did not meet the inclusion criteria or did not complete the survey correctly, 5,157 respondents formed the sample (Figure 1). The baseline characteristics of these respondents are provided in Table 1. Their ages ranged between 10 and 91 years. The gender ratio (M:F in \%) was 67.3:32.7. They had varying levels of education, and experience in yoga, as well as different occupations. The signed informed consent of each respondent was taken as part of the survey.

\section{Design}

The study was a one-time cross-sectional survey. The total number of participants exceeded 25,000. The selected sample size was 15,000 . This was not based on statistical calculations but on pragmatic considerations. Administering the survey simultaneously to 15,000 participants posed practical difficulties. Hence, it was decided to administer the survey when participants were seated in smaller groups. Buses were arranged to transport participants from a specific point to the venue. There were 50 participants in each bus. Hence, 300 buses were selected so as to get the required number of 15,000 respondents. No standard methods of randomization were used to select buses, which is a definite limitation of the survey. The survey was administered by a volunteer (one volunteer/stationary bus). The volunteers had been briefed about the survey questions. There were no specific considerations for participants to enter a bus and entry was free. The study had prior clearance from the ethical committee

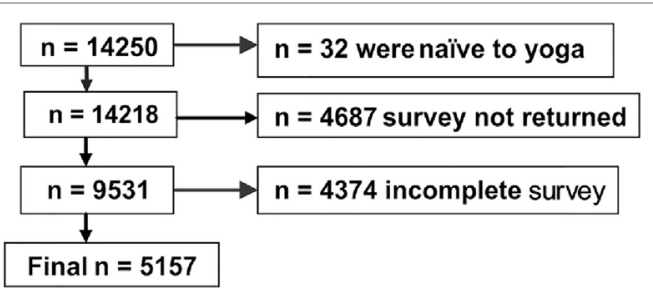

FIGURE 1 | Details about the number of respondents.

TABLE 1 | Baseline characteristics of the participants.

\begin{tabular}{lc}
\hline Characteristics & Details \\
\hline Age (years) & \\
Group mean age (SD) & $33.4(17.3)$ \\
Age range & $10-91$ \\
Gender: male:female (actual values), \% values & $3,469: 1,688,67.3: 32.7$ \\
Years of education (\%) & \\
10 years and less & 39.2 \\
11-12 years & 23.2 \\
13-15 years & 24.2 \\
16 years and above & 13.2 \\
Experience of yoga (\%) & \\
Less than a month & 7.1 \\
1-12 months & 54.4 \\
13-60 months & 23.8 \\
60 months and above & 14.7
\end{tabular}


of Patanjali Research Foundation (approval no. PRF/16/0023), which was formed based on the guidelines of the Indian Council of Medical Research (9).

\section{The Event and Yoga Protocol}

The event was in New Delhi on June 19, 2016 in a public space with multiple entrances. The event was organized by a yoga institution in north India (viz., Patanjali Yogpeeth). Entry was free and unrestricted. The grounds were easily accessible. Participants were given yoga mats to practice yoga or to observe others practice. Naïve-to-yoga participants were instructed to be observers. The event involved yoga practices from the common yoga protocol developed by the Ministry of AYUSH, Government of India (10), devised to be practiced across India on International Yoga Day. These techniques were considered relatively safe for all yoga practitioners. Contraindications for practice were mentioned. The 45-min protocol included a universal prayer, loosening exercises, yoga postures, yoga breathing techniques, and meditation. The details are given in Table 2.

\section{The Survey}

The survey was written in both English and Hindi. It had three parts: (i) Details about the respondents: age, gender, education, occupation, and experience in yoga, (ii) the primary reason why the participants wanted to practice yoga, and (iii) the yoga practice they liked the most. Participants were asked to sign an informed consent form. The second part of the survey, i.e., the primary reason to practice yoga had 10 possible responses with examples. These were (i) arranged in alphabetical order in English, (ii) given serial numbers, and (iii) the sequence of the 10 options was randomized using a standard randomizer (www.randomizer. org). Each person was asked to select one option which they rated as their primary reason to practice yoga. The authors' experience with yoga practice and research (from 1991 till the present time) (11-13) was taken into account to develop the survey.

For the third part of the survey, the yoga practices were selected based on (i) the eight limbs (asthang in Sanskrit) of yoga, described by the sage Patanjali (Circa 900 B.C.) (14) and (ii) the yoga practices commonly taught in India (15). There were six

TABLE 2 | The 45-min yoga protocol devised by the Ministry of AYUSH, Government of India (10).

\begin{tabular}{|c|c|c|}
\hline Sl. no. & Type of practice & Duration (min) \\
\hline 1 & Prayer in any meditative posture with Namaskara Mudra and ending with Yoga Mudrasana & 2 \\
\hline 2 & Sadilaja/Chaalan Kriyas/loosening practices (neck, shoulders, trunk, and knees movements) & 6 \\
\hline \multirow[t]{5}{*}{3} & $\begin{array}{l}\text { Light exercises and specific yoga postures (asanas) } \\
\text { I. Standing postures } \\
\text { - Taadaasana (palm tree pose) } \\
\text { - Vrikshaasana (tree pose) } \\
\text { - Pada-hastaasana/Uttaanaasana (hand to foot pose/standing forward bend pose) } \\
\text { - Ardha chakraasana (standing backward bend pose) } \\
\text { - Trikonaasana (triangle pose) }\end{array}$ & 18 \\
\hline & $\begin{array}{l}\text { II. Sitting postures } \\
\text { - Bhadraasana/Baddhakonaasan (butterfly pose) } \\
\text { - Vajrasana/Veerasana (thunderbolt pose/hero pose) } \\
\text { - Ushtraasana (Ardha for beginners)(camel pose) } \\
\text { - Shashankaasan (rabbit pose) } \\
\text { - Utthana Mandukasana (stretched frog pose) } \\
\text { - Marichyaasana/Vakraasana (ray of light pose/curved pose) }\end{array}$ & \\
\hline & $\begin{array}{l}\text { III. Prone lying postures } \\
\text { - Makaraasana (crocodile pose) } \\
\text { - Bhujangaasana (cobra pose) } \\
\text { - Shalabhaasana (locust pose) }\end{array}$ & \\
\hline & IV. Supine lying postures & \\
\hline & $\begin{array}{l}\text { - Setubandhasana (bridge pose) } \\
\text { - Utthanapaadaasana (leg raised pose) } \\
\text { - ArdhaHalasana (half plough pose) } \\
\text { - PawanaMuktaasana (wind relieving pose) } \\
\text { - Shavaasan (corpse pose) }\end{array}$ & \\
\hline 4 & $\begin{array}{l}\text { - Kapalabhati (3 cycles of } 40 \text { strokes each) (kapala = forehead; bhati = shining; rapid, forceful exhalations) } \\
\text { Each cycle will be followed deep breathing }\end{array}$ & 3 \\
\hline 5 & $\begin{array}{l}\text { Pranayama } \\
\text { - NadiShodhana/AnulomaViloma Pranayama (alternate nostril breathing) (5 rounds) } \\
\text { - Sheetali Pranayama (cooling breath) (5 rounds) } \\
\text { - Bhramari Pranayama (bee breathing) (5 rounds) }\end{array}$ & 6 \\
\hline 6 & Dhyana/Meditation in any Meditative Posture (eyes closed) and hands in Inana/Gyana Mudra & 8 \\
\hline 7 & $\begin{array}{l}\text { End of the yoga Practice Session with a Sankalp } \\
\text { Total duration }\end{array}$ & $\begin{array}{r}2 \\
45\end{array}$ \\
\hline
\end{tabular}


options written in English and given their Sanskrit name. These 6 options were then randomized as described above for the 10 options in the second part of the survey. The final sequence is presented in Table 3. Each respondent was asked to select their first choice out of the six options.

\section{Data Extraction}

Survey sheets were sorted for different characteristics such as age, gender, years of education, occupation, and experience of yoga. Under each category, the number of respondents who were practicing yoga for a specific reason was noted. Similarly, the yoga practice of choice was noted for respondents under each category, for example, male and female. Handling this volume of data is prone to error. Hence, each entry was checked by two researchers, independently.

\section{Data Analyses}

The values were converted as a percentage of the whole within each category. The percentages have been used in the discussion. They have been provided for the reasons to practice yoga (Table 4) and for the yoga practices of choice (Table 5). Also, the percentage values were used to carry out separate Chi square tests to detect differences between-groups in the responses to the two questions (i.e., the primary reason to practice yoga and the yoga practice of choice), under the categories: age, gender, years of education, occupation, and experience in yoga.

\section{RESULTS}

The first most common reason for all respondents to practice yoga was physical fitness. Three motivators, i.e., (i) disease management

\begin{tabular}{|c|c|c|}
\hline $\begin{array}{l}\text { Part of the } \\
\text { survey }\end{array}$ & Section & Options \\
\hline Part II & $\begin{array}{l}\text { Motivators to } \\
\text { practice yoga based } \\
\text { on the question: } \\
\text { why do you want to } \\
\text { practice yoga? }\end{array}$ & $\begin{array}{l}\text { Disease management (e.g., diabetes, } \\
\text { hypertension) } \\
\text { Belief with no specific reasons (that is as a } \\
\text { part of faith) } \\
\text { Mental development (e.g., increase memory) } \\
\text { As a hobby } \\
\text { Physical strength (e.g., muscle strength) } \\
\text { Spiritual growth (e.g., sadhana) } \\
\text { Because my friends practice it } \\
\text { Emotional health (e.g., relief from depression) } \\
\text { Because my guru says I should } \\
\text { Belief based on scientific knowledge (e.g., } \\
\text { books or research publications) }\end{array}$ \\
\hline Part III & $\begin{array}{l}\text { Choice of yoga } \\
\text { practice based on } \\
\text { the question: which } \\
\text { practice of yoga do } \\
\text { you like the most? }\end{array}$ & $\begin{array}{l}\text { Yamas and Niyamas } \\
\text { Asanas } \\
\text { Pranayamas } \\
\text { Kriyas } \\
\text { Mudras and Bandhas } \\
\text { Meditation }\end{array}$ \\
\hline
\end{tabular}

The sequence for options for both Part II and Part III has been randomized. Part I included socio-demographic data sheet.

Participants were instructed to select one option that was most appropriate for part II and similarly for Part III. $\left(\chi^{2}=17.62, p<0.005\right)$, (ii) yoga as a hobby $\left(\chi^{2}=10.87, p<0.05\right)$, and (iii) practicing yoga because my guru says to practice it $\left(\chi^{2}=20.05\right.$, $p<0.001$ ) differed significantly between the five age ranges (i.e., $10-12,13-20,21-44,45-59$, and 60 years and above).

The yoga practice of choice also differed significantly between the different age groups: (i) asanas $\left(\chi^{2}=23.17, p<0.001\right.$ ), (ii) pranayamas $\left(\chi^{2}=19.87, p<0.001\right)$, and meditation $\left(\chi^{2}=9.64\right.$, $p<0.05)$. Pranayamas as the practice of choice differed significantly with occupations $\left(\chi^{2}=9.62, p<0.05\right)$.

\section{DISCUSSION}

5,157 respondents completed a survey in June 2016 in New Delhi, India. There were more males $(67.3 \%)$ compared to females (32.7\%).

The maximum respondents were adults between 21 and 44 years (33.7\%), followed by adolescents between 13 and 20 years (31.7\%) (16). Children between 10 and 12 years were least (4.0\%) and seniors 60 years and above were $9.4 \%$.

Most yoga practitioners had between 8 and 10 years of education (39.2\%). Ten years is equal to a basic school leaving certificate. The smallest percentage had at least 16 years of education (13.2\%). This corresponds to post-graduation and further studies.

The respondents could be broadly categorized into five occupations. Students formed the highest percentage (39.3\%) while retired persons were the fewest $(3.5 \%)$. There is an increased interest in young people to be physically fit and the number of young people choosing to practice yoga has increased all over India (3). A contributing factor could partly be that younger persons would be expected to be more enthusiastic about such an outdoor event and also would find the venue more accessible.

Among the respondents, the maximum number had experience of yoga ranging from 1 to 12 months (54.4\%). This could be related to the fact that the maximum respondents were students.

Hence, in the present survey in India, more yoga practitioners were male, aged between 21 and 44 years with education between 8 and 10 years, students, and with 1 and 12 months experience of yoga. These results contrasted with those obtained in the US, where yoga practitioners were more often female, between 40 and 64 years of age (4) or with an average age of 39.5 years (5), with a minimum of college education, and a greater likelihood of being White, non-Hispanic, and Caucasian $(4,5)$. In Australia too, participants were more often female, with an average age of 41 years and were tertiary educated (6). The gender ratio in this study resembles that of a survey carried out in west India in Mumbai, on 972 practitioners (7) where males exceeded females (54.8:45.2). The results differed from the results of another survey conducted in India on 280 persons who had self-selected to join for a 1-month yoga residential course (8). Among the 280 respondents, the number of males and females was comparable, i.e., 48:52. In this study, despite the large number of participants, there was adequate space and security measures; hence, it is unlikely that these factors influenced the participation of females. The other factors (e.g., 8-10 years of education, more students practicing yoga in India) which differed between surveys conducted in India versus the US or Australia may be attributed to 


\begin{tabular}{|c|c|c|c|c|c|c|c|c|c|c|c|c|}
\hline \multirow[b]{3}{*}{ Characteristics } & & \multirow[b]{3}{*}{$\begin{array}{l}\text { Total } \\
\text { sample }\end{array}$} & \multicolumn{10}{|c|}{ Reasons to practice yoga } \\
\hline & & & \multicolumn{2}{|r|}{2} & \multirow{2}{*}{$\begin{array}{c}3 \\
\begin{array}{c}\text { Yoga for } \\
\text { mental } \\
\text { development }\end{array}\end{array}$} & \multirow{2}{*}{$\begin{array}{c}4 \\
\begin{array}{c}\text { Yoga as a } \\
\text { hobby* }\end{array}\end{array}$} & \multirow{2}{*}{$\begin{array}{c}5 \\
\begin{array}{c}\text { Yoga for physical } \\
\text { fitness }\end{array}\end{array}$} & \multirow{2}{*}{\begin{tabular}{|c|}
6 \\
Yoga for \\
spiritual \\
growth
\end{tabular}} & \multirow{2}{*}{$\begin{array}{c}7 \\
\text { Because } \\
\text { friends } \\
\text { practice } \\
\text { yoga }\end{array}$} & \multirow{2}{*}{$\begin{array}{c}8 \\
\begin{array}{c}\text { Yoga for } \\
\text { emotional } \\
\text { health }\end{array}\end{array}$} & \multirow{2}{*}{$\begin{array}{c}9 \\
\text { Because } \\
\text { my guru } \\
\text { (teacher) } \\
\text { says }^{\star}\end{array}$} & \multirow{2}{*}{$\begin{array}{c}10 \\
\begin{array}{c}\text { Belief based } \\
\text { on scientific } \\
\text { knowledge }\end{array}\end{array}$} \\
\hline & & & $\begin{array}{l}\text { Yoga for disease } \\
\text { management }^{\star}\end{array}$ & $\begin{array}{c}\text { Blind faith in } \\
\text { yoga }\end{array}$ & & & & & & & & \\
\hline 1. Gender & $\begin{array}{l}\text { Male } \\
\text { Female }\end{array}$ & $\begin{array}{l}3,469 \\
1,688\end{array}$ & $\begin{array}{l}438(12.6 \%) \\
227(13.4 \%)\end{array}$ & $\begin{array}{r}148(4.3 \%) \\
63(3.7 \%)\end{array}$ & $\begin{array}{l}347 \text { (10.0\%) } \\
179(10.6 \%)\end{array}$ & $\begin{array}{l}191(5.5 \%) \\
100(5.9 \%)\end{array}$ & $\begin{array}{r}1,667(48.1 \%) \\
895(53.0 \%)\end{array}$ & $\begin{array}{r}295(8.5 \%) \\
99(5.9 \%)\end{array}$ & $\begin{array}{l}59(1.7 \%) \\
14(0.9 \%)\end{array}$ & $\begin{array}{l}27(0.8 \%) \\
16(0.9 \%)\end{array}$ & $\begin{array}{r}116(3.3 \%) \\
40(2.4 \%)\end{array}$ & $\begin{array}{r}181(5.2 \%) \\
55(3.3 \%)\end{array}$ \\
\hline 2. Age (in years) & $\begin{array}{l}10-12 \\
13-20 \\
21-44 \\
45-59 \\
60 \text { and above }\end{array}$ & $\begin{array}{r}208 \\
1,642 \\
1,739 \\
1,081 \\
487\end{array}$ & $\begin{array}{c}13(6.3 \%) \\
129(7.9 \%) \\
199(11.4 \%) \\
203(18.7 \%) \\
121(24.8 \%)\end{array}$ & $\begin{array}{r}9(4.3 \%) \\
66(4.0 \%) \\
66(3.8 \%) \\
42(3.9 \%) \\
28(5.7 \%)\end{array}$ & $\begin{array}{c}28(13.5 \%) \\
205(12.5 \%) \\
187(10.8 \%) \\
76(7.0 \%) \\
30(6.2 \%)\end{array}$ & $\begin{array}{c}30(14.4 \%) \\
115(7.0 \%) \\
75(4.3 \%) \\
50(4.6 \%) \\
21(4.3 \%)\end{array}$ & $\begin{array}{r}88(42.3 \%) \\
833(50.7 \%) \\
930(53.5 \%) \\
502(46.4 \%) \\
209(42.9 \%)\end{array}$ & $\begin{array}{c}4(1.9 \%) \\
90(5.5 \%) \\
141(8.1 \%) \\
112(10.4 \%) \\
47(9.7 \%)\end{array}$ & $\begin{array}{r}1(0.5 \%) \\
38(2.3 \%) \\
17(1.0 \%) \\
13(1.2 \%) \\
04(0.8 \%)\end{array}$ & $\begin{array}{l}2(1.0 \%) \\
17(1.0 \%) \\
17(1.0 \%) \\
06(0.7 \%) \\
01(0.3 \%)\end{array}$ & $\begin{array}{l}26(12.5 \%) \\
69(4.2 \%) \\
32(1.8 \%) \\
23(2.1 \%) \\
06(1.2 \%)\end{array}$ & $\begin{array}{r}7(3.3 \%) \\
80(4.9 \%) \\
75(4.3 \%) \\
54(5.0 \%) \\
20(4.1 \%)\end{array}$ \\
\hline $\begin{array}{l}\text { 3. Education } \\
\text { (in years) }\end{array}$ & $\begin{array}{l}10 \text { years and } \\
\text { below }\end{array}$ & 2,023 & $273(13.5 \%)$ & $85(4.2 \%)$ & $207(10.2 \%)$ & $133(6.6 \%)$ & $986(48.7 \%)$ & $132(6.5 \%)$ & $39(1.9 \%)$ & $14(0.8 \%)$ & $83(4.1 \%)$ & 71 (3.5\%) \\
\hline & $11-12$ years & 1,202 & $147(12.2 \%)$ & 47 (3.9\%) & $145(12.1 \%)$ & $74(6.2 \%)$ & $588(48.9 \%)$ & $82(6.8 \%)$ & $16(1.3 \%)$ & $15(1.3 \%)$ & $41(3.4 \%)$ & 47 (3.9\%) \\
\hline & 13-15 years & 1,250 & 153 (12.2\%) & $53(4.2 \%)$ & 117 (9.4\%) & 55 (4.4\%) & 645 (51.6\%) & 114 (9.1\%) & $11(0.9 \%)$ & $9(0.7 \%)$ & $26(2.1 \%)$ & 67 (5.4\%) \\
\hline & $\begin{array}{l}16 \text { years and } \\
\text { above }\end{array}$ & 682 & $92(13.5 \%)$ & $26(3.8 \%)$ & $57(8.4 \%)$ & $29(4.3 \%)$ & $343(50.3 \%)$ & $66(9.7 \%)$ & $7(1.0 \%)$ & $5(0.6 \%)$ & $6(0.9 \%)$ & $51(7.5 \%)$ \\
\hline $\begin{array}{l}\text { 4. Experience in } \\
\text { yoga }\end{array}$ & $\begin{array}{l}\text { Less than } \\
1 \text { month }\end{array}$ & 365 & 47 (12.9\%) & $18(4.9 \%)$ & $35(9.6 \%)$ & $25(6.8 \%)$ & $181(49.6 \%)$ & $19(5.2 \%)$ & $10(2.8 \%)$ & $5(1.4 \%)$ & $15(4.1 \%)$ & $10(2.7 \%)$ \\
\hline & 1-12 months & 2,805 & 320 (11.4\%) & 110 (3.9\%) & 335 (11.9\%) & 158 (5.6\%) & 1,465 (52.2\%) & 162 (5.8\%) & 46 (1.7\%) & $21(0.8 \%)$ & 90 (3.2\%) & 98 (3.5\%) \\
\hline & $13-60$ months & 1,228 & $171(13.9 \%)$ & $53(4.3 \%)$ & $114(9.3 \%)$ & 69 (5.6\%) & $593(48.3 \%)$ & $114(9.3 \%)$ & $12(1.0 \%)$ & $12(1.0 \%)$ & $33(2.7 \%)$ & $57(4.6 \%)$ \\
\hline & $\begin{array}{l}60 \text { months and } \\
\text { above }\end{array}$ & 759 & $127(16.7 \%)$ & $30(4.0 \%)$ & $42(5.5 \%)$ & 39 (5.1\%) & $323(42.6 \%)$ & $99(13.0 \%)$ & $5(0.7 \%)$ & $5(0.7 \%)$ & $18(2.3 \%)$ & $71(9.4 \%)$ \\
\hline 5. Occupations & Students & 2,028 & $159(7.8 \%)$ & 77 (3.8\%) & $267(13.2 \%)$ & $159(7.8 \%)$ & 1,007 (49.7\%) & $106(5.2 \%)$ & 39 (1.9\%) & $20(1.0 \%)$ & 95 (4.7\%) & 99 (4.9\%) \\
\hline & Employed & 1,070 & $143(13.4 \%)$ & $47(4.4 \%)$ & $97(9.1 \%)$ & 47 (4.4\%) & 534 (49.9\%) & 103 (9.6\%) & $15(1.4 \%)$ & $8(0.8 \%)$ & $22(2.0 \%)$ & $54(5.0 \%)$ \\
\hline & Self-employed & 844 & $141(16.7 \%)$ & 33 (3.9\%) & $65(7.7 \%)$ & 38 (4.5\%) & $373(44.2 \%)$ & 107 (12.7\%) & $11(1.3 \%)$ & $6(0.7 \%)$ & $23(2.7 \%)$ & 47 (5.6\%) \\
\hline & Homemakers & 781 & 132 (16.9\%) & 29 (3.7\%) & 59 (7.5\%) & 29 (3.7\%) & 452 (57.9\%) & 44 (5.6\%) & 5 (0.7\%) & $5(0.7 \%)$ & 8 (1.0\%) & $18(2.3 \%)$ \\
\hline & Retired & 182 & 38 (20.9\%) & 15 (8.2\%) & $13(7.1 \%)$ & 9 (4.9\%) & 83 (45.6\%) & 10 (5.5\%) & 2 (1.1\%) & $1(0.6 \%)$ & 2 (1.1\%) & $9(5.0 \%)$ \\
\hline & Not mentioned & 252 & 52 (20.6\%) & $10(3.9 \%)$ & 25 (9.9\%) & 9 (3.6\%) & $113(44.8 \%)$ & 24 (9.5\%) & 1 (0.5\%) & $3(1.2 \%)$ & $6(2.4 \%)$ & $9(3.6 \%)$ \\
\hline
\end{tabular}

${ }^{*} \chi^{2} p<0.05$ across age groups. 
TABLE 5 | The 6 yoga practices provided as options in a random sequence to the 5,157 respondents.

\begin{tabular}{|c|c|c|c|c|c|c|c|c|}
\hline \multirow[b]{3}{*}{ Characteristics } & & \multirow[b]{3}{*}{ Sample size } & \multicolumn{6}{|c|}{ Yoga practices } \\
\hline & & & 1 & 2 & 3 & 4 & 5 & 6 \\
\hline & & & Yama-niyams & Asanas* & Pranayama*,@ & Kriyas & $\begin{array}{l}\text { Mudras- } \\
\text { Bandhas }\end{array}$ & Meditation* \\
\hline \multirow[t]{2}{*}{ 1. Gender } & Male & 3,469 & 194 (5.6\%) & $842(24.3 \%)$ & $1493(43.0 \%)$ & $79(2.3 \%)$ & $44(1.2 \%)$ & $817(23.6 \%)$ \\
\hline & Female & 1,688 & 69 (4.1\%) & $501(29.7 \%)$ & 733 (43.4\%) & $33(2.0 \%)$ & $13(0.7 \%)$ & $339(20.1 \%)$ \\
\hline \multirow[t]{5}{*}{ 2. Age (in years) } & $10-12$ & 208 & $10(4.8 \%)$ & 102 (49.0\%) & 58 (27.9\%) & $3(1.4 \%)$ & 2 (1.0\%) & 33 (15.9\%) \\
\hline & $13-20$ & 1,642 & 66 (4.0\%) & $545(33.2 \%)$ & $463(28.2 \%)$ & $43(2.6 \%)$ & $18(1.1 \%)$ & 507 (30.9\%) \\
\hline & $21-44$ & 1,739 & $83(4.7 \%)$ & 407 (23.4\%) & 803 (46.2\%) & $46(2.7 \%)$ & $18(1.0 \%)$ & $382(22.0 \%)$ \\
\hline & $45-59$ & 1,081 & $72(6.7 \%)$ & $194(17.9 \%)$ & $628(58.1 \%)$ & $12(1.1 \%)$ & $14(1.3 \%)$ & $161(14.9 \%)$ \\
\hline & 60 and above & 487 & $32(6.6 \%)$ & 95 (19.5\%) & $274(56.3 \%)$ & $8(1.6 \%)$ & $05(1.0 \%)$ & $73(15.0 \%)$ \\
\hline \multirow[t]{4}{*}{ 3. Education (in years) } & 10 years & 2,023 & $110(5.4 \%)$ & $592(29.3 \%)$ & $773(38.2 \%)$ & $51(2.5 \%)$ & $30(1.5 \%)$ & $467(23.1 \%)$ \\
\hline & $11-12$ years & 1,202 & 72 (6.0\%) & $293(24.4 \%)$ & 476 (39.6\%) & $29(2.4 \%)$ & $11(0.9 \%)$ & $321(26.7 \%)$ \\
\hline & $13-15$ years & 1,250 & $59(4.7 \%)$ & $286(22.9 \%)$ & $621(49.7 \%)$ & $22(1.8 \%)$ & $9(0.7 \%)$ & $253(20.2 \%)$ \\
\hline & 16 years and above & 682 & $22(3.2 \%)$ & $172(25.2 \%)$ & $356(52.2)$ & $10(1.5 \%)$ & $7(1.0 \%)$ & $115(16.9 \%)$ \\
\hline \multirow[t]{4}{*}{ 4. Experience in yoga } & Less than 1 month & 365 & 22 (6.0\%) & 96 (26.3\%) & 123 (33.7\%) & $8(2.2 \%)$ & $2(0.6 \%)$ & $114(31.2 \%)$ \\
\hline & $1-12$ months & 2,805 & $127(4.5 \%)$ & $805(28.7 \%)$ & $1,101(39.3 \%)$ & $69(2.5 \%)$ & $34(1.1 \%)$ & $669(23.9 \%)$ \\
\hline & $13-60$ months & 1,228 & 61 (5.0\%) & 305 (24.8\%) & 583 (47.5\%) & $28(2.3 \%)$ & $16(1.3 \%)$ & 235 (19.1\%) \\
\hline & 60 months and above & 759 & $53(7.0 \%)$ & $137(18.0 \%)$ & $419(55.2 \%)$ & $7(0.9 \%)$ & $5(0.7 \%)$ & 138 (18.2\%) \\
\hline \multirow[t]{6}{*}{ 5. Occupations } & Students & 2,028 & 79 (3.9\%) & 688 (33.9\%) & $584(28.8 \%)$ & $51(2.5 \%)$ & $23(1.2 \%)$ & $603(29.7 \%)$ \\
\hline & Employed & 1,070 & 65 (6.1\%) & 224 (20.9\%) & $547(51.1 \%)$ & $25(2.4 \%)$ & $15(1.4 \%)$ & $194(18.1 \%)$ \\
\hline & Self-employed & 844 & 59 (7.0\%) & 169 (20.0\%) & 439 (52.0\%) & $15(1.8 \%)$ & $10(1.2 \%)$ & $152(18.0 \%)$ \\
\hline & Homemakers & 781 & 39 (4.9\%) & $175(22.4 \%)$ & 419 (53.6\%) & 17 (2.3\%) & $5(0.7 \%)$ & $126(16.1 \%)$ \\
\hline & Retired & 182 & 9 (4.9\%) & 45 (24.7\%) & 98 (53.8\%) & $0(0.0 \%)$ & $1(0.7 \%)$ & $29(15.9 \%)$ \\
\hline & Not mentioned & 252 & $12(4.8 \%)$ & 42 (16.7\%) & $139(55.2 \%)$ & $4(1.6 \%)$ & $3(1.1 \%)$ & $52(20.6 \%)$ \\
\hline
\end{tabular}

${ }^{*} \chi^{2} p<0.05$ for asanas, pranayama, and meditation across age groups.

${ }^{\circledR} \chi^{2} p<0.05$ pranayama across occupation.

aims and aspirations of young people in a developing economy such as India (17).

We mentioned 10 reasons in the survey that could motivate participants to practice yoga. The first most common reason for all respondents to practice yoga was physical fitness. Selecting physical fitness as a primary reason to practice yoga is comparable to the results of the survey in Australia (6) and surveys in the US $(4,5)$.

Three motivators (i.e., practicing yoga as a hobby, practicing based on a guru's instructions and for disease management) differed significantly between the five age ranges. The 10- to 12-year age group chose "practicing yoga as a hobby" which was significantly higher in comparison to the percentages of the four other age groups (i.e., 13-20, 21-44, 45-59, and 60 years and above). For children to practice yoga as a hobby is a healthy trend which should be encouraged (18). The reasons why children chose "yoga as a hobby" as a motivating factor could be many; there is an increased attempt to introduce yoga in schools in India to alleviate stress and reduce the growing incidence of childhood obesity (19). It is important to mention here that despite yoga having been introduced in certain schools in India, yoga is not treated as a subject for which students have a regular examination. This could allow children to learn yoga without a feeling of performance anxiety and stress. Apart from this in India, there are several sports persons and other celebrities who promote yoga, which may have influenced the way in which children perceive yoga practice (20). Practicing yoga "based on a gurus's instructions" was also significantly higher in children between
10 and 12 years age group compared to the percentages of the four other age groups (i.e., 13-20, 21-44, 45-59, and 60 years and above). This was an interesting trend in pre-teens and could be related to observations that Asian parents tended to be more authoritarian than their Caucasian counterparts (21). This also suggests that despite an increased awareness of freedom which pre-teens have in many cultures (22), in India traditional values appear to prevail in a large percentage of pre-teens. It is debatable whether it is ideal that children of this age should be so dependent on instructions from their guru. Some parents allow children of this age too much of the wrong kind of freedom or they offer freedom before the adolescent is ready to accept it. Other parents cling too tightly, denying pre-teens both the responsibilities they require to develop maturity and the opportunities they need to make choices and accept their consequences. The present results suggest that the attitude of these pre-teens requires to be reviewed. Respondents aged between 21 and 60 years and above selected disease management as their second most common reason to practice yoga. This could be related to the increased incidence of non-communicable diseases such as diabetes and hypertension in middle-aged persons in India $(23,24)$, as well as a growing awareness that yoga and healthy lifestyle choices can help in the management of these diseases (25).

The third part of the survey provided information about the yoga practice the participants were most likely to choose. The factors which significantly influenced the choice of yoga practice were age and occupation. 
Children between 10 and 12 years and adolescents (13-20 years) selected asanas as their first choice of practice. A possible reason is that most children prefer being active to sitting still as is required for pranayama and meditation practice (26). Also, asanas are known to improve physical fitness (27). This is supported by the findings of the survey, i.e., children and adolescents chose yoga to improve physical fitness as their primary reason to practice yoga.

Adults chose pranayama as their first choice and, asanas as their second choice of practice. The practice of asanas requires flexibility (28), while pranayama can also be practiced by those who are less mobile (29) or less flexible. It is well known that both mobility and flexibility reduce with age (30). This may explain why adults selected pranayama as their first choice of practice whereas for children and adolescents asanas were their first choice of practice.

The results of this survey show a significant difference between the percentages of respondents who selected pranayama as their primary choice of practice for different occupations. Out of five occupations, respondents from four categories of occupations selected pranayama as their first choice of practice. These were (i) employed, (ii) self-employed, (iii) retired, and (iv) homemakers. Pranayama practice is more popular in India than elsewhere, and specific sets of practices (15) and techniques such as Sudarshan Kriya Yoga (31) are practiced widely across the country. Apart from this, middle aged and older adults who have not been physically active often find pranayama easier to practice (32). Students' first two most common choices were asanas and meditation. Hence, the finding that pranayama as a primary choice of practice varies with the type of occupation, could be related to other factors, such as the age of the respondents and their level of physical activity and fitness. None of the respondents selected yamas/niyamas, mudras/bandhas, or kriyas as their first choice of yoga practice.

In summary, more yoga practitioners were male, aged between 21 and 44 years, with education between 8 and 10 years, students, and with 1 and 12 months experience of yoga. The first most common reason to practice yoga for all respondents was physical fitness. Three of the remaining reasons to practice yoga differed significantly with age: (i) yoga for disease management, (ii) yoga as a hobby, and (iii) yoga based on the guru's (teacher's) instructions. The yoga technique

\section{REFERENCES}

1. Kuvalayananda S. Asanas. Lonavala: Kaivalyadhama (1993).

2. United Nations. General Assembly 69th Meeting. (2014). Available from: https:// www.un.org/press/en/2014/ga11601.doc.htm

3. Ahmed SK. Number of Yoga Practitioners Soars by Up to 30 Per Cent Across Indian Metros: Survey. (2016). Available from: http://indianexpress.com/ article/india/india-news-india/number-of-yoga-practitioners-soars-by-up-to30-per-cent-across-indian-metros-survey/

4. Cramer H, Hall H, Leach M, Frawley J, Zhang Y, Leung B, et al. Prevalence, patterns, and predictors of meditation use among US adults: a nationally representative survey. Sci Rep (2016) 6:36760. doi:10.1038/srep36760

5. Birdee GS, Legedza AT, Saper RB, Bertisch SM, Eisenberg DM, Phillips RS. Characteristics of yoga users: results of a national survey. J Gen Intern Med (2008) 23:1653-8. doi:10.1007/s11606-008-0735-5 of choice [i.e., (i) asanas, (ii) pranayama, or (iii) meditation] differed significantly across age groups.

All respondents selected physical fitness as their primary reason to practice yoga. Three motivators (i.e., practicing yoga as a hobby, disease management, and practicing based on a guru's instructions) differed significantly between the five age ranges. The choice of yoga practice was influenced by age and occupation significantly.

The findings of this survey are limited by the method of sampling. Despite this limitation, the results represent people from across the Indian subcontinent. A further systematically conducted survey would help to substantiate the findings.

\section{ETHICS STATEMENT}

The study had prior clearance from the ethical committee of Patanjali Research Foundation (approval no. PRF/16/0023) which was formed based on the guidelines of the Indian Council of Medical Research.

\section{AUTHOR CONTRIBUTIONS}

SS collected and analyzed the data. ST drafted the manuscript. SS and NS assisted in compiling the revised manuscript, ST, AB, and SS contributed to the study design and interpretation of results. ST and SS will act as guarantors.

\section{ACKNOWLEDGMENTS}

The authors gratefully acknowledge the help of Patanjali Yog Samiti Delhi and especially Dr. Jaideep Arya, Chief Central Coordinator of Patanjali Yog Samiti, Haridwar, Uttarakhand, India. The meticulous arrangement of data by Deepshikha Tyagi, Babita Vishwakarma, Sushma Pal, Kumar Gandharva, Savita Agnihotri, Karuna Chaudhary, Alok Singh, Niranjan Kala, Sadhna Verma, and Ankit Gupta was an important and indispensable contribution.

\section{FUNDING}

The study was funded by the Divya Yog Mandir (Trust), Patanjali Yogpeeth, Haridwar, Uttarakhand, India.

6. Penman S, Cohen M, Stevens P, Jackson S. Yoga in Australia: results of a national survey. Int J Yoga (2012) 5:92-101. doi:10.4103/0973-6131.98217

7. Tiwari S, Telles S, Goel A, Verma A. Beliefs of yoga practitioners about yoga as a science. A survey in Mumbai. Yoga Mimamsa (2014) 46:15-9. doi:10.4103/0044-0507.140195

8. Dayananda H, Ilavarasu JV, Rajesh S, Babu N. Barriers in the path of yoga practice: an online survey. Int J Yoga (2014) 7:66-71. doi:10.4103/0973-6131.123490

9. Indian Council of Medical Research. Ethical Guidelines for Biomedical Research on Human Participants. (2006). Available from: http://www.icmr. nic.in/ethical_guidelines.pdf

10. Ministry of AYUSH. Common Yoga Protocol 2016. (2016). Available from: http:// ayush.gov.in/event/common-yoga-protocol-2016-0

11. Swami Vivekananda Yoga Anusandhana Samsthana. Compilation of Research Publications 1985-2001. Bengaluru: Swami Vivekananda Yoga Prakashan (2001). 
12. Swami Vivekananda Yoga Anusandhana Samsthana. Compilation of Research Publications 2002-2011. Bengaluru: Swami Vivekananda Yoga Prakashan (2011).

13. Patanjali Research Foundation. Research Publications (2007-2015). Haridwar: Divya Prakashan (2015).

14. Singh AN. Role of yoga therapies in psychosomatic disorders. Int Congr Ser (2006) 1287:91-6. doi:10.1016/j.ics.2005.11.096

15. Ramdev S. Pranayama Rahasya. Haridwar: Divya Prakashan (2000).

16. The Rhode Island Department of Health. Adolescence (13-21 Years) Maternal and Child Health Facts. (2009). Available from: http://www.amchp.org/programsandtopics/WorkforceDevelopment/Documents/5\%20RI\%20FY11\%20 MCH\%20Factsheet\%20Adolescence.pdf

17. Gutta S, Sahay R. 6 Things to Know About Our India Economic Summit 2016. (2016). Available from: https://www.weforum.org/agenda/2016/10/6things-to-know-about-our-india-economic-summit-2016/

18. Khalsa SB, Butzer B. Yoga in school settings: a research review. Ann N Y Acad Sci (2016) 1373:45-55. doi:10.1111/nyas.13025

19. Unnikrishnan AG, Kalra S, Garg MK. Preventing obesity in India: weighing the options. Indian JEndocrinol Metab (2012) 16:4-6. doi:10.4103/2230-8210.91174

20. Dutta N. The 20 Fittest Indian Sportsmen. (2014). Available from: http://www. thehealthsite.com/fitness/the-20-fittest-indian-sportsmen-n314/

21. Chang M. Cultural Differences in Parenting Styles and Their Effects on Teens' Self-Esteem, Perceived Parental Relationship Satisfaction, and Self Satisfaction. (2007). Available from: http://repository.cmu.edu/cgi/viewcontent. cgi? article $=1084 \&$ context $=$ hsshonors

22. U.S. Department of Education. Independence - Helping Your Child through Early Adolescence. Available from: https://www2.ed.gov/parents/academic/ help/adolescence/part7.html (accessed June 17, 2017).

23. Malik R. India Is the Diabetes Capital of the World. (2016). Available from: http://timesofindia.indiatimes.com/life-style/health-fitness/healthnews/India-is-the-diabetes-capital-of-the-world/articleshow/50753461. $\mathrm{cms}$

24. Kishore J, Gupta N, Kohli C, Kumar N. Prevalence of hypertension and determination of its risk factors in rural Delhi. Int J Hypertens (2016) 2016:7962595. doi:10.1155/2016/7962595
25. Press Trust of India. Yoga Can Help Control Non-Communicable Diseases. (2016). Available from: http://www.financialexpress.com/india-news/ yoga-can-help-control-non-communicable-diseases-j-p-nadda/293816/

26. Blatt-Gross C. Why Do WeMakeStudents SitStillin Class?(2015). Availablefrom: http://www.edition.cnn.com/2014/03/30/living/no-sitting-still-movementschools

27. Hagins M, Moore W, Rundle A. Does practicing hatha yoga satisfy recommendations for intensity of physical activity which improves and maintains health and cardiovascular fitness? BMC Complement Altern Med (2007) 7:40. doi:10.1186/1472-6882-7-40

28. Our Fitness House. Yoga Poses for Flexibility. Available from: http://www.ourfitnesshouse.com/yoga-poses-for-flexibility.html (accessed January 19, 2017).

29. Ramanathan M. Yoga for the Differently-Abled Children. Available from: http://icyer.com/documents/YOGA\%20FOR\%20THE\%20DISABLED.pdf (accessed January 19, 2017).

30. Milanović Z, Pantelić S, Trajković N, Sporiš G, Kostić R, James N. Age-related decrease in physical activity and functional fitness among elderly men and women. Clin Interv Aging (2013) 8:549-56. doi:10.2147/CIA.S44112

31. Zope SA, Zope RA. Sudarshan Kriya yoga: breathing for health. Int J Yoga (2013) 6:4-10. doi:10.4103/0973-6131.105935

32. Marshall RS, Basilakos A, Williams T, Love-Myers K. Exploring the benefits of unilateral nostril breathing practice post-stroke: attention, language, spatial abilities, depression, and anxiety. J Altern Complement Med (2014) 20:185-94. doi:10.1089/acm.2013.0019

Conflict of Interest Statement: The authors declare that the research was conducted in the absence of any commercial or financial relationships that could be construed as a potential conflict of interest.

Copyright ( $(2017$ Telles, Sharma, Singh and Balkrishna. This is an open-access article distributed under the terms of the Creative Commons Attribution License (CC BY). The use, distribution or reproduction in other forums is permitted, provided the original author(s) or licensor are credited and that the original publication in this journal is cited, in accordance with accepted academic practice. No use, distribution or reproduction is permitted which does not comply with these terms. 